http://jmscr.igmpublication.org/home/ ISSN (e)-2347-176x ISSN (p) 2455-0450 crossref DOI: https://dx.doi.org/10.18535/jmscr/v8i8.45

\title{
Etiology of Pancytopenia in a Study in a Tertiary Care Hospital in North Andhra
}

\author{
Authors \\ Dr S.Sreenivas ${ }^{1}$, Dr Marri Lakshmi Harika ${ }^{2}$, Dr Tati Hyma ${ }^{3}$, Dr Gadipudi Mounika ${ }^{4}$ \\ ${ }^{1}$ Professor, ${ }^{2,3,4}$ Post Graduate \\ Department of General Medicine \\ King George Hospital
}

\begin{abstract}
Background: pancytopenia is defined as the simultaneous existence of anemia, leukopenia, thrombocytopenia. It is encountered in day to day clinical practice. Knowing the underlying cause determines the appropriate management. The aim of the study was to obtain the common causes causing pancytopenia in patients admitted in tertiary care hospital in north Andhra and the frequency of various etiological factors.

Materials and Methods: This prospective observational study was done in the department of general medicine in tertiary hospital over 7 months period from January 2020 to July 2020. History, blood investigations, the peripheral smear was done for all patients and bone marrow examination was done for selected patients.

Results: out of 100 patients 61 were male and 39 were female. Megaloblastic anemia was the commonest cause that was observed followed by aplastic anemia, chronic liver disease, haematological malignancy, infections like HIV and malaria, SLE.

Conclusion: The most common cause of pancytopenia in this part of India is megaloblastic anemia which is a curable deficiency.

Keywords: pancytopenia, megaloblastic anemia, aplastic anemia.
\end{abstract}

\section{Introduction}

Pancytopenia is defined as a reduction of all three major formed elements in the blood; erythrocytes, leukocytes and platelets. Manifestations depend on the severity of anemia, leukopenia and thrombocytopenia. WHO defines anemia as haemoglobin level $<13 \mathrm{~g} / \mathrm{dl}$ in men and $<12 \mathrm{~g} / \mathrm{dl}$ in women. Leucopenia defined as WBC count $<4000$ cells/cumm. Thrombocytopenia defined as platelet count $<1.5$ lakhs/cumm.

The causes of pancytopenia can be due to decreased hematopoietic cell production, increased destruction of marrow tissue or increased peripheral destruction of blood cells, infiltration of marrow by abnormal or malignant tissue, and ineffective haematopoiesis.

Pancytopenia with Hypocellular Bone Marrow includes Acquired aplastic anemia, Constitutional aplastic anemia, myelodysplastic syndrome, aleukemic leukemia, acute lymphoid leukaemia, lymphomas of bone marrow, Copper deficiency. pancytopenia with Cellular Bone Marrow includes Myelodysplastic syndromes, Systemic lupus erythematosus, Paroxysmal nocturnal 
haemoglobinuria (PNH), Hypersplenism, B12, folate deficiency, Copper deficiency, Myelofibrosis, Alcohol, HIV infection, Myelophthisis, Brucellosis, lymphoma, Sarcoidosis, Hairy cell leukaemia, Tuberculosis, Leishmaniasis, Sepsis.

\section{Aims and Objectives}

To determine the causes of pancytopenia by conducting a study on case history, blood investigations, blood smear and bone marrow aspiration/biopsy findings for an appropriate management as early as possible. To know the frequency of various etiologic factors.

\section{Materials and Methods}

The present prospective study was undertaken for a period of 7 months, from January 2020 to July 2020 in the medicine department at a tertiary care hospital in north Andhra. Patients of age groups 13-72years and both sexes were included. Case selection was based on clinical features and supported byperipheral blood counts for hemoglobin, leukocytes and platelets.

A total number of 100 cases of pancytopenia were included after taking informed consent.

In all patients, relevant medical history including age, gender, smoking status, alcohol intake, history of any treatment, intake of or exposure to potentially toxic chemicals, agents or drugs, radiation exposure, history of bone pains, fever, night sweats, malaise, weight loss and pruritus was taken. A detailed physical examination of every patient was done for pallor, jaundice, hepatosplenomegaly, lymphadenopathy, sternal tenderness and gum hypertrophy.

Basic haematological investigations like CBC, reticulocyte count, and peripheral smear examination were performed in each case. A bone marrow examination was done in selected patients. Other investigations performed included ESR, urine and stool examination, liver and renal function tests, other serological investigations; the investigative workup being directed by the suspected underlying pathology and the provisional diagnoses.

\section{Inclusion Criteria}

All patients $>13 y$ rs presenting in medicine OPD or ward with pancytopenia.

\section{Exclusion Criteria}

1. Patients age $<13$ yrs.

2. Patients on cancer chemotherapy/ radiotherapy.

3. Patient with mono and bicytopenia.

4. Patient who had a previous blood transfusion before smear study.

\section{Results}

Out of 100 patients, 61 were male and 39 were female patients. Male to female ratio is 1.56:1.

Table 1: Gender-Wise Distribution of Patients

\begin{tabular}{|l|c|c|}
\hline Sex & Number of patients & Percentage \\
\hline Male & 61 & $61 \%$ \\
\hline Female & 39 & $39 \%$ \\
\hline Total & 100 & $100 \%$ \\
\hline
\end{tabular}

Out of 100 patients, 36 patients were in the age group of 13-32, 42 patients were in the age group of $33-52,22$ patients were in the age group of more than 52 yrs.

\section{age wise distribution}

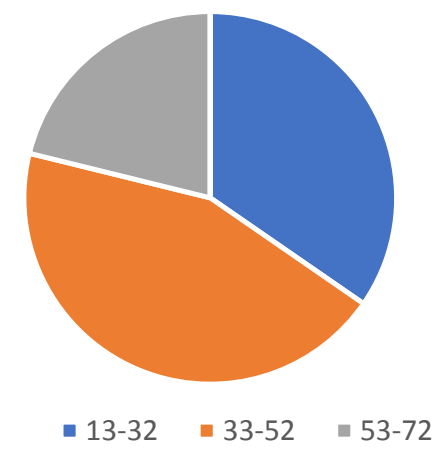

Figure 1: Age-Wise Distribution of Patients

Out of 100 cases bone marrow was done for 60 cases, among which few were suggestive of aplastic anemia, one was suggestive of leukaemia and others were suggestive of megaloblastic 
anemia. Remaining showed improvement with provisional diagnoses and etiology specific treatment hence bone marrow examination was not performed.

Out of 100 cases, 64 were diagnosed to have megaloblastic anemia, 10 turned out to be aplastic anemia, 8 were chronic liver disease (hypersplenism), 8 was HIV induced,6 were SLE, 2 were malaria, 1 was leukemia, 1 was dengue fever.

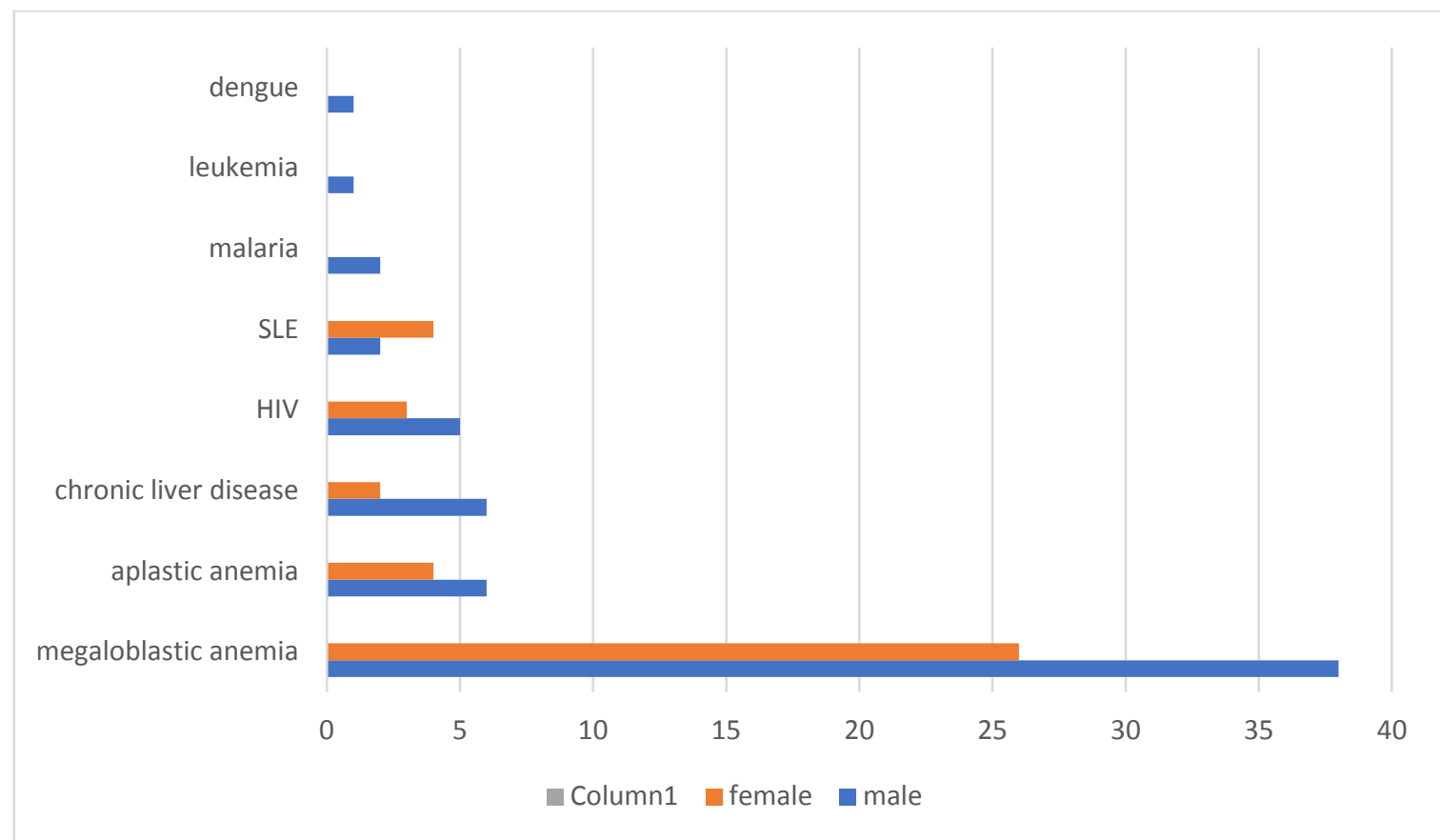

Figure -2: Sex Wise Distribution of aetiology

Table 2: Age Wise Distribution of individual etiology

\begin{tabular}{|l|c|c|c|}
\hline Aetiology & $\begin{array}{c}\text { Number of cases } \\
\text { 13-32 Age group }\end{array}$ & $\begin{array}{c}\text { Number of cases } \\
33-52 \\
\text { Age group }\end{array}$ & $\begin{array}{c}\text { Number of cases } \\
53-72 \\
\text { Age group }\end{array}$ \\
\hline Megaloblastic anemia & 20 & 30 & 14 \\
\hline Aplastic anemia & 10 & 0 & 0 \\
\hline Chronic liver disease & 0 & 4 & 4 \\
\hline HIV & 1 & 4 & 3 \\
\hline SLE & 4 & 2 & 0 \\
\hline Malaria & 0 & 1 & 1 \\
\hline Leukemia & 1 & 0 & 0 \\
\hline Dengue & 0 & 1 & 0 \\
\hline Total & 36 & 42 & 22 \\
\hline
\end{tabular}

\section{Discussion}

Pancytopenia is not a disease but a manifestation of various illnesses. It has varied manifestations which may be due to anemia, thrombocytopenia and sometime life-threatening leukopenia. It can be an incidental finding. From pathogenesis point of view, the causes can be categorized as follows:

1. Reduced formation in the marrow.
2. Cell death in marrow due to ineffective erythropoiesis.

3. Defective cell formation which is avidly removed by circulation.

4. Destruction of cells due to the action of antibodies.

5. Trapping of normal cells due to overactive and hypertrophied reticuloendothelial system. 
The most common cause of pancytopenia in the present study was megaloblastic anemia in 64\% cases. The increased incidence of megaloblastic anemia can be correlated to the increased prevalence of nutritional deficiency in our country. The male to female ratio was 1.46:1. Incidence of $72 \%$ was reportedby Khunger et al and $74 \%$ by Gayathri and Rao. The incidence of megaloblastic anemia in similar studies varied from $0.8-80 \%$.

Megaloblastic anemia is a group of disorder characterized by defective nuclear maturation caused by impaired DNA synthesis. Majority of patients had macrocytic and hypochromicanemia, Hyper segmented neutrophils. Bone marrow was hypercellular with megaloblastic erythropoiesis and giant metamyelocytes. Megakaryocytes were normal.

In this study $10 \%$ cases were diagnosed asaplastic anemia. The male to female ratio is 1.5:1. These results are similar to studies done by Tilak et al in which a $7.7 \%$ incidence of a plastic anemia was found and Raphael et al where $8.7 \%$ of the cases of pancytopenia presented with a plastic anemia.

Aplastic anemia is defined as the failureof bone marrow to produce blood cells. The hallmarks of the disease are pancytopenia and hypocellular bone marrow.

In this study chronic liver disease is cause in 8\% patients.Pancytopenia in chronic liver disease can be due to hypersplenism (most common), megaloblastic anemia, and primary marrow suppression. Hypersplenism is a clinical syndrome characterized by enlargement of spleen, reduction of at least one cell line in the blood in the presence of normal marrow function, increased release of premature cells from the bone marrow into the blood. Hypersplenism is a treatable cause of pancytopenia.

HIV accounted for $8 \%$ of cases presenting as pancytopenia in this study. Pancytopenia in HIV has been attributed to many causes which include inflammatory cytokines or HIV virus itself, infiltration by lymphoma or infections, polypharmacy, disseminated intravascular coagulation, thrombotic thrombocytopenic purpura, auto-antibodies and malnutrition.

$6 \%$ cases in the present study with pancytopenia had connective tissue disorder (SLE). Studies were done by Azaad et al and Osama et alalso state SLE as one of the causes of pancytopenia with an incidence of $4 \%$ and $6 \%$ respectively.

In this present study, 1 patient of pancytopenia was diagnosed with leukemia. Immature cells including myeloblast were seen. Bone marrow was hypercellular with blast $>20 \%$.

Malaria was present in 2 of the total cases in our study. The peripheral blood smear showed gametocytes of plasmodium vivax. Studies conducted by Dasgupta et al had 2\% incidence of malaria with pancytopenia while those by Gayathri and Raohad an incidence of $1.93 \%$. Bone marrow was hypercellular in malaria.

The last cause was dengue in 1 out of all cases which may be due to hypersplenism, hemophagocytosis, or immune haemolysis. Infections and post-viral illness have been reported to be responsible for pancytopenia.

Table-3: Comparison of the most common cause of pancytopenia in different studies

\begin{tabular}{|l|c|c|c|c|c|}
\hline Study & Country & Year & No of cases & Most common cause & Second most common cause \\
\hline Tilak et al & India & 1998 & 77 & Megaloblastic anemia & Aplastic anemia \\
\hline Khadka et al & India & 2000 & 166 & aplastic anemia & Megaloblasticanemia \\
\hline Khunger et al & India & 2002 & 200 & Megaloblastic anemia & Aplastic anemia \\
\hline Gayathri and ral & India & 2011 & 104 & Megaloblastic anemia & Aplastic aneemia \\
\hline Jain and naniwadekar & India & 2013 & 250 & hypersplenism & Infection \\
\hline Sweta et al & India & 2014 & 100 & Megaloblastic anemia & Aplastic aneemia \\
\hline Dasgupta et al & India & 2015 & 248 & Aplastic anemia & Megaloblastic anemia \\
\hline Present study & India & 2020 & 100 & Megaloblastic anemia & Aplastic anemia \\
\hline
\end{tabular}




\section{Conclusion}

The present study on pancytopenia concludes that detailed haematological investigations, bone marrow examination provide information in the evaluation of pancytopenia.

In our study the most common cause of pancytopenia is megaloblastic anemia.In India poor eating habits, poverty, poor quality of foods, lack of education and self avoidance of necessary foods may be causes of nutritional deficiency which leading to megaloblastic anemia. Hence most of the vegetarian population in our country should be supplemented with regular intake of Vitamin B-12 and folic acid to avoid the occurrence of megaloblastic anemia.

There are other treatable causes like dengue, malaria, where pancytopenia resolves over a period of time after aetiology specific treatment is given. However, bone marrow becomes necessary if there is no improvement or there are signs which are suggestive of severe diseases like leukaemia, MDS etc.

\section{Limitations}

The study is done in a limited number of patients in one region. Results may vary in a large number of subjects and various regions and food habits of people.

\section{Source of Funding: None \\ Conflicts of Interest: None}

\section{References}

1. Khodke K, Marwah S, Buxi G, Yadav RB, Chaturvedi NK. Bone marrow examination in case of pancytopenia. $\mathrm{J}$ Indian Aca Clin Med 2001; 2:55-9.

2. Tilak V, Jain R. Pancytopenia - a clinic hematologic analysis of 77 cases. Indian J Pathol Microbiol 1999;42:399-404

3. Gayathri BN, Rao KS. Pancytopenia: A clinicohematological study. J Lab Physicians 2011; 3:15-20.
4. Raphael V, Khonglah Y, Dey B, Gogoi P, Bhuyan A, et al. Pancytopenia: An Etiological Profile. Turk J Hematol 2012; 29: 80-81.

5. Dasgupta S, Mandal PK, Chakrabarti S. Etiology of Pancytopenia: An observation from a referral medical institution of Eastern Region of India. J Lab Physicians 2015; 7:90-5.

6. Azaad MA, Li YP, Zhang QR and Wang HX. Detection of Pancytopenia Associated with Clinical Manifestation and Their Final Diagnosis. Open Journal of Blood Diseases 2015; 5:17-30.

7. Jain A, Naniwadekar M. An etiological reappraisal of pancytopenia - Largest series reported to date from a single tertiary care teaching hospital. BMC Hematol 2013; 13:10.

8. Study of Pancytopenia in a Tertiary Care Hospital in North Karnataka Kulkarni Naveen S*, Patil Appu S, and Karchi SD General Medicine, S. Nijalingappa Medical College and H. S. K. Hospital \& Research Centre, Navanagar Bagalkot, Karnataka, India.

9. The Common Causes Leading to Pancytopenia in Patients Presenting in Hospital of Central India T. N. Dubey1, Preeti Nigotia2, Rita Saxena3

10. Suryaresmi BS, Abraham L, Mathew A, Raj JM. The etiological spectrum of pancytopenia diagnosed from blood smears examined in the pathology department of a rural tertiary care centre in South India. Int J Med Sci Public Health 2018;7(2):126-131.

11. Etiological and clinical spectrum of pancytopenia based on bone marrow examination and case records: A retrospective study Prashanth B Gandhil, Tharanath Shankar1, Mohammed IAfraz Pasha2*, Mangala Gouri. 